\title{
Comparación del acento léxico del español y dos tonos estándar del chino mandarín en palabras aisladas: El contorno tonal
}

\author{
Junming Yao \\ Universidad Internacional Menéndez Pelayo \\ yaojunming@yahoo.com
}

\begin{abstract}
Submitted: 20 de diciembre de 2013. Accepted: 10 de abril de 2014. Available on line: 2 de marzo de 2015
Citation / Cómo citar este artículo: Yao, J. (2014). Comparación del acento léxico del español y dos tonos estándar del chino mandarín en palabras aisladas: El contorno tonal. Loquens, 1(2), e010. doi: http://dx.doi.org/10.3989/loquens.2014.011

RESUMEN: El presente trabajo trata de un estudio comparativo del chino mandarín y el español, dos idiomas muy diferentes. Se estudia la relación entre el contorno del acento léxico del español con dos tonos estándar del chino mandarín a través de un experimento con palabras pronunciadas aisladamente. De esta manera verificamos la semejanza entre el acento léxico de las palabras paroxítonas (no hiatos) y proparoxítonas españolas y el primer tono del chino mandarín, así como entre el acento léxico de las palabras oxítonas españolas y el cuarto tono del chino mandarín. Dichos resultados podrían servir como base teórica para la enseñanza-aprendizaje del español por sinohablantes y viceversa.
\end{abstract}

Palabras clave: español; chino mandarín; acento léxico; tonos; semejanza de contorno.

ABSTRACT: A comparison of Spanish lexical stress and two standard Mandarin tones in isolated words: The tonal contour.- This comparative study investigates the relationship between the contour of the word-level stress in Spanish and that of two standard tones in Mandarin Chinese, namely the first and the fourth tones. The experiment was carried out with isolated Spanish words. Contour similarity was found between the word-level stress in Spanish paroxytone (non-hiatus) and proparoxytone words and the first Chinese tone, as well as between the stress in oxytone words and the fourth tone. These results could be used in teaching Spanish to Chinese students and vice versa.

Keywords: Spanish; Mandarin Chinese; word-level stress; tones; contour similarity.

\section{INTRODUCCIÓN}

El chino mandarín y el español son dos idiomas tipológicamente distintos. Se refleja, entre otros aspectos, en la función de la frecuencia fundamental $\left(f_{0}\right)$. El chino mandarín es una lengua tonal. En dicho idioma, la $f_{0}$ tiene función léxica aparte de intervenir en la entonación a nivel oracional. Es decir, cada sílaba tiene su propio tono, el cual, junto con otros componentes (consonantes y vocales), define el significado de dicha sílaba. En cambio, el español es una lengua entonativa, en la cual la $f_{0}$ no interviene en la semántica de una palabra, sino que, como la duración y la intensidad, es un correlato acústico del acento léxico y también interviene en la entonación a nivel oracional. Es más, es el factor determinante para distinguir la sílaba tónica de la átona (Enríquez, Casado, \& Santos, 1989; Llisterri, Machuca, de la Mota, Riera, \& Ríos, 2005; Quilis, 1971). Esta diferencia entre los dos idiomas dificulta el proceso de enseñanza-aprendizaje de la entonación ya desde el primer momento. Por ejemplo, muchos estudiantes chinos no distinguen ni producen bien la sílaba tónica del español; los estudiantes españoles no distinguen ni producen bien los tonos silábicos del chino.

Sin embargo, podría existir algo en común entre los dos idiomas que sirva para solucionar los problemas mencionados, en concreto, entre los tonos de uno y el acento léxico del otro, en lo cual consiste el estudio del presente trabajo. Es un tema que no ha sido tratado hasta hoy, ni tampoco entre chino e inglés, aunque existen estudios acústicos sobre la semejanza entre el tono neutro del chino y la sílaba átona del inglés (Lin, 1985; Xu \& Xu, 2005).

Como primera aproximación a este estudio comparado, empezamos la investigación con palabras aisladas, dejando para un estudio posterior el análisis de palabras inmersas en un contexto. 
Estudiamos el contorno del acento léxico del español a través de la vocal tónica. Postulamos que el contorno tonal de dicha vocal, cuando una palabra se pronuncia de forma aislada (no en un contexto de frase), se puede aproximar a los valores estándar de algunos contornos tonales del chino mandarín. En concreto: 1. El contorno tonal de la vocal tónica de las palabras paroxítonas (no hiatos) y proparoxítonas del español es parecido o incluso igual que el primer tono estándar del chino mandarín. 2. El contorno tonal de la vocal tónica de las palabras oxítonas del español es parecido o incluso igual que el cuarto tono estándar del chino mandarín.

Con el fin de valorar estas hipótesis, hemos realizado un análisis acústico de $f_{0}$ para encontrar las relaciones entre las sílabas tónicas del español y los tonos del chino mandarín. Estos últimos ya están estudiados y estandarizados cuando se pronuncian separadamente, por lo que nuestro análisis se basa en estudios anteriores (Chao, 1930/2006; Comité Nacional de Lengua y Escritura, 2004; Lin, 1965; Shi, 2008; Wang, 2003). En el caso del español, estudiamos la diferencia en semitonos (st) entre las frecuencias máxima y mínima de la vocal tónica para ver su contorno global a través de un corpus pronunciado por hablantes nativos.

La semejanza entre los tonos del chino mandarín y el acento léxico del español sería, en cierto modo, un indicio de que existen universales en la prosodia de los diferentes idiomas. Por otro lado, serviría a la enseñanza de un idioma como segunda lengua.

La Sección 2 consiste en una breve presentación de los tonos estándar del chino mandarín, la Sección 3 describe el experimento y los resultados, y las conclusiones se encuentran en la Sección 4.

\section{LOS TONOS DEL CHINO MANDARÍN}

El mandarín estándar es la lengua oficial de la República Popular China, Taiwán y una de las cuatro lenguas oficiales de Singapur ${ }^{1}$. En este trabajo usamos el término chino mandarín para referirnos al mandarín estándar que se usa en la República Popular China, conocido oficialmente como putonghua [普通话 pǔtōnghuà].

El chino mandarín es una lengua tonal. Se usan, además de consonantes y vocales, tonos para distinguir sílabas y palabras. En otros términos, la $f_{0}$ tiene función léxica. En dicho idioma, cada sílaba tiene su propio tono, el cual, junto con las consonantes y vocales, define el significado de la sílaba.

\subsection{Cuatro tonos estándar}

Hay cuatro tonos estándar en el chino mandarín: el primero, tono alto y sostenido [阴平 yīnpíng]; el segun- do, tono ascendente [阳平yángpíng]; el tercero, tono bajo descendente-ascendente [上声 shàngshēng]; y el cuarto, tono descendente [去声 qùshēng]. Un ejemplo muy citado es el de la distinción de tonos y significados entre $m \bar{a}$ [妈] ('mamá'), má [麻] ('lino'), mă [马] ('caballo') y mà [骂] ('reñir'). De hecho, se pueden encontrar innumerables ejemplos parecidos. Aquí sólo elegimos uno más: $d \bar{a}$ [搭] ('montar'), dá [答] ('contestar'), dǎ [打] ('pegar'), dà [大] ('grande').

Además, existe un tono neutro, llamado también tono ligero o tono cero. Su contorno tonal varía según la sílaba precedente (Comité Nacional de Lengua y Escritura, 2004; Tsukuma, 1988; Wang, 2003). Por tanto, no es un tono concreto, y no se puede considerar como el quinto tono del chino mandarín. Acústicamente, una sílaba con el tono neutro es semejante a la sílaba átona de las lenguas entonativas como el inglés, al menos en términos de duración (Lin, 1985) y $f_{0}(\mathrm{Xu} \& \mathrm{Xu}, 2005)$. La intensidad no es un parámetro relevante para dicho tono. La impresión de ligereza es una consecuencia de su corta duración (Lin, 1990).

\subsubsection{Modelo de descripción de cinco niveles}

El sistema tradicional y ampliamente aceptado para la anotación de los tonos es el de cinco niveles propuesto por Chao (1930/2006). Consiste en dividir una línea vertical en cuatro partes equivalentes consiguiendo cinco puntos numerados como 1, 2, 3, 4 y 5, los cuales corresponden a bajo, semi-bajo, medio, semi-alto y alto, respectivamente. Dicho sistema describe la altura y el contorno relativos entre tonos dentro de un mismo campo tonal, y sirve para describir cualquier tipo de tono, tanto de registro como de contorno $^{2}$. En Rose (2014) se discute, a través de datos de dos dialectos chinos, sobre la precisión de dicho sistema para describir los tonos, pero en otros estudios se comprueba su validez para la descripción de los cuatro tonos del chino mandarín, los cuales se denominan [55], [35], [214] y [51] (véase la Figura 1). Los contornos tonales que representan estos valores los obtuvo Chao (1922) primero a través de test de percepción con instrumentos musicales, pero también están comprobados con aparatos de análisis acústico por estudiosos posteriores como Lin (1965) y Shi (2008). Además, es la descripción estándar de los cuatro tonos utilizada por el Comité Nacional de Lengua y Escritura (2004), equivalente a la RAE. Dicha descripción también sirve como criterio en la formación de la pronunciación de tonos para ciertas profesiones como, por ejemplo, presentadores, locutores o profesores (Wang, 2003).

De hecho, es difícil encontrar un tono producido exactamente con los valores estándar en el habla real. En realidad, cada tono tiene un campo de dispersión. Por tanto, se puede interpretar cada línea tonal de la Figura 1 como la línea central de toda una banda (Shi, 2008).

\footnotetext{
${ }^{1}$ Las otras tres son inglés, malayo y tamil.

${ }^{2}$ Tenemos cinco puntos en el eje de altura tonal. Si dividimos el eje de duración en tres partes iguales, en teoría obtendremos $5^{3}=125$ tonos. No obstante, cada lengua solo elige una pequeña parte de todas esas posibilidades para formar su sistema tonal (Shi, 2009).
} 
Figura 1: Contornos tonales de los cuatro tonos estándar del chino mandarín según Chao (1930/2006).

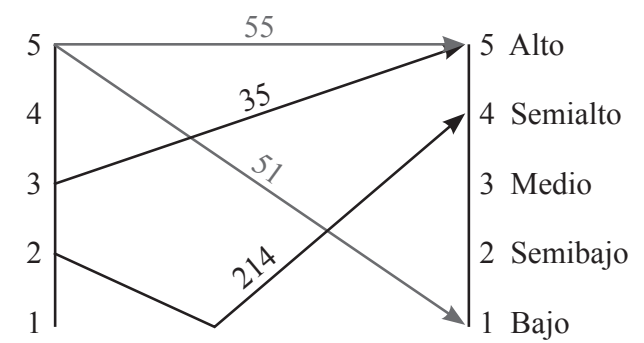

\subsubsection{Fórmula de conversión: valores de frecuencia a valores de cinco niveles}

Cada persona tiene su propio nivel tonal y rango tonal. Los picos y valles del contorno de $f_{0}$ no se miden con valores absolutos sino que se han de tener en cuenta los factores propios de cada individuo. La escala tonal del sistema presentado está normalizada para poder comparar las curvas realizadas por distintos locutores en un mismo campo tonal. Además, los valores absolutos no son relevantes, sino los cinco niveles relativos, pues en los cuatro tonos léxicos del chino mandarín solo se consideran los saltos tonales durante la producción.

Shi (2008) propone una fórmula para convertir un valor de frecuencia $(\mathrm{Hz})$ en un valor relativo dentro de cinco niveles en bandas:

$$
T=5 \frac{\log x-\log b}{\log a-\log b^{\prime}}
$$

donde $a$ es la frecuencia máxima del campo tonal del hablante en la producción, $b$ la frecuencia mínima, y la magnitud $x$ es la frecuencia del punto cuyo valor relativo $T$ vamos a calcular.

Dicha fórmula da valores de 0 a 5 , es decir, son seis los puntos que dividen el campo tonal en cinco bandas. Por tanto, si $T \in[0,1]$, corresponde al valor 1 del sistema de Chao (1930/2006) (§ 2.1.1); si $T \in[0,2]$, corresponde al valor 2 , y así sucesivamente, hasta $T \in[0,5]$, que equivale al valor 5 .

A partir de la fórmula anterior, dado que la relación entre hercios y semitonos viene dada por

$$
s t=\frac{12}{\log 2} \log H z
$$

deducimos de forma inmediata la fórmula análoga para convertir semitonos en valores relativos de cinco niveles:

$$
T=5 \frac{X-B}{A-B^{\prime}},
$$

donde $A$ es la frecuencia máxima del campo tonal de las producciones de un hablante, $B$ es la frecuencia mínima, y la magnitud $X$ es la frecuencia del punto cuyo valor relativo $T$ vamos a calcular.

\section{EXPERIMENTO}

Con nuestro experimento tratamos de analizar los valores acústicos de $f_{0}$ de la vocal tónica del español. Consiste en estudiar la diferencia entre las frecuencias máxima y mínima de dicha vocal para observar su contorno tonal general y compararlo con algunos tonos estándar del chino mandarín. Utilizamos Praat (v. 5.1.24) como herramienta para conseguir los datos necesarios.

Comparamos datos fonéticos con datos fonológicos, que son más abstractos en tanto que están en una escala relativa de cinco puntos. Sin embargo, convertimos los datos fonéticos a la misma escala para poder llevar a cabo la comparación.

\subsection{Hipótesis}

Hipótesis 1: El contorno tonal de la vocal tónica de las palabras paroxítonas (no hiatos) y proparoxítonas del español, pronunciadas aisladamente, no en un contexto de frase, es parecido o incluso igual que el primer tono estándar del chino mandarín.

Hipótesis 2: El contorno tonal de la vocal tónica de las palabras oxítonas del español pronunciadas aisladamente (no en un contexto de frase) es parecido o incluso igual que el cuarto tono estándar del chino mandarín.

\subsection{Corpus}

Nuestras hipótesis se formulan a nivel general con palabras pronunciadas aisladamente, independientemente de las vocales que corresponden a la sílaba tónica, de su combinación con distintas consonantes y del número de sílabas de la palabra. Para poder comprobar las hipótesis, creamos un corpus con las siguientes características:

- En principio usamos logatomos (por ejemplo, «apa») para poder controlar mejor las combinaciones silábicas, pero también existen palabras reales (por ejemplo, «papá») que aparecieron de manera natural al aplicar los siguientes criterios de combinación:

- Construimos palabras paroxítonas de dos y tres sílabas (por ejemplo, «pipa», «apipa»), proparoxítonas de tres y cuatro sílabas (por ejemplo, «pépapa», «apépapa»), y oxítonas de una y dos sílabas (por ejemplo, «pop», «papó»), de modo que pudiéramos discriminar la posible influencia del número de sílabas.

- En las paroxítonas bisilábicas y proparoxítonas trisilábicas tenemos palabras con y sin consonante delante de la sílaba tónica (por ejemplo, «ipa», «pipa»; «ópapa», «pópapa»), y en las oxítonas, con y sin consonante final en la última sílaba, que es tónica (por ejemplo, «po», «pop»), por lo cual comprobamos si su existencia influye en el resultado. 
- Para cada una de las diez combinaciones que se obtienen de los dos puntos anteriores, hicimos variar la vocal tónica entre las cinco posibles (por ejemplo, «ipa», «epa», «apa», «ора», «upa») para discriminar su posible influencia.

- Así construimos un total de 50 palabras donde las vocales átonas se limitan a la central baja /a/ y las consonantes a la oclusiva sorda /p/, lo cual se debe a que las sílabas átonas quedan fuera del estudio según nuestras hipótesis, y si las mantenemos iguales, podemos reducir las variables. Por otra parte, hemos elegido /p/ para las sílabas tónicas, de manera que se separe más fácilmente la vocal de la consonante.

\subsection{Informantes}

Con el fin de establecer la independencia de nuestras hipótesis respecto del sexo y la edad, reunimos cuatro informantes nativos españoles, dos hombres y dos mujeres, de entre 28 y 68 años, todos con estudios superiores. Cada informante pronunció una vez las 50 palabras, por lo que, en total, son $50 \times 4=200$ producciones. Para un estudio más avanzado en el futuro, sería necesario un número más grande de informantes con diferencias en su nivel de estudios y edad.

\subsection{Grabación}

Grabamos con Praat (v. 5.1.24) bajo un sistema Linux los tres tipos de palabras de nuestro corpus con los informantes masculinos $(\mathrm{H})$ y femeninos $(\mathrm{M})$. La grabación en mono no se hizo directamente a través del micrófono incorporado en el ordenador, sino con un micrófono externo de marca AIWA. La frecuencia de muestreo fue de 44 $\mathrm{kHz}$ y la resolución de 16 bits. Guardamos los ficheros en formato WAV. Pasamos todos los ficheros por Audacity para filtrar los ruidos de la grabación. En este paso se intentó reducir al máximo la pérdida en los sonidos objeto de estudio. Para ello obtuvimos el perfil de ruido a través del espectro y sólo quitamos esos elementos de ruido sin afectar al sonido principal. Después normalizamos la intensidad de la grabación debido a que nuestras hipótesis se basan fundamentalmente en la $f_{0}$.

En Praat anotamos manualmente las consonantes y las vocales de cada palabra con su transcripción fonética (vocal tónica en mayúscula) y guardamos los ficheros en formato TextGrid para facilitar el acceso a los datos más adelante.

\subsection{Datos}

Para cada muestra utilizamos las siguientes notaciones:

- $F_{\text {med }}$ es la frecuencia media de la vocal tónica,

- $F_{\text {máx }}$ es la frecuencia máxima de la vocal tónica,

- $F_{\text {mín }}$ es la frecuencia mínima de la vocal tónica,

- $t_{\text {máx }}$ es el tiempo en el que se alcanza $F_{\text {máx }}$,
- $t_{\text {min }}$ es el tiempo en el que se alcanza $F_{\text {mín }}$,

y definimos la diferencia tonal (DT) como

$$
D T:=F_{\text {máx }}-F_{\text {mín }},
$$

y la variación tonal (VT) como

$$
V T:= \begin{cases}D T, & \text { Si } t_{\text {mín }}<t_{\text {máx }} \\ -D T, & \text { Si } t_{\text {mín }}>t_{\text {máx }}\end{cases}
$$

De estas dos definiciones, se deducen de manera inmediata los siguientes hechos:

1. DT siempre es positiva, pues siempre $F_{\text {máx }}>F_{\text {mín' }}$, luego indica la magnitud de variación de la frecuencia de la vocal tónica, independientemente de si el tono es ascendente o descendente.

2. DT es el valor absoluto de $V T$.

3. $V T$ positiva equivale a que la vocal tónica presenta tono ascendente, ya que $F_{\text {mín }}$ se alcanza antes que $F_{\text {máx }}$.

4. VT negativa equivale a que la vocal tónica presenta tono descendente, ya que $F_{\text {máx }}$ se alcanza antes que $F_{\text {min }}$.

5. Tanto $V T$ como $D T$ se refieren exclusivamente a la vocal tónica.

La Tabla 1 contiene los valores medios de las frecuencias máximas, las mínimas y la $V T$ de la vocal tónica en semitonos según el tipo de palabras y el sexo de informantes.

Tabla 1. Valores medios en semitonos (st) de las frecuencias máximas y mínimas, y variación tonal de las vocales tónicas según el tipo de palabras y el sexo de los hablantes. $\mathrm{H}=$ Hombre, $\mathrm{M}=$ Mujer.

\begin{tabular}{lcrrr}
\hline \multirow{2}{*}{ Palabras } & & \multicolumn{2}{c}{ Frecuencia (st) } & \\
\cline { 2 - 4 } Paroxítonas & Sexo & máx. & mín. & VT (st) \\
\hline \multirow{2}{*}{ Proparoxítonas } & $\mathrm{H}$ & 4,4 & 3,6 & 0,8 \\
\cline { 2 - 4 } & $\mathrm{M}$ & 12,7 & 12,0 & 0,7 \\
\cline { 2 - 4 } & $\mathrm{H}$ & 6,3 & 5,6 & 0,7 \\
\hline \multirow{2}{*}{ Oxítonas } & $\mathrm{M}$ & 11,5 & 10,3 & 1,2 \\
\hline & $\mathrm{H}$ & 5,0 & 2,5 & $-2,5$ \\
\hline & $\mathrm{M}$ & 11,7 & 9,1 & $-2,6$ \\
\hline
\end{tabular}

Además de los datos anteriores, la Tabla 2 muestra la frecuencia media de las vocales tónicas y átonas de cada informante en palabras paroxítonas y proparoxítonas.

\subsection{Análisis de los resultados}

\subsubsection{Reformulación de las hipótesis}

Como indica la Figura 1, se usa una misma escala para medir los cuatro tonos chinos, y esa escala no corres- 
Tabla 2. Frecuencia media en hercios $(\mathrm{Hz})$ y semitonos $(\mathrm{st})$ de las vocales tónicas y átonas por hablante en palabras paroxítonas y proparoxítonas. $\mathrm{H}=$ Hombre, $\mathrm{M}=$ Mujer.

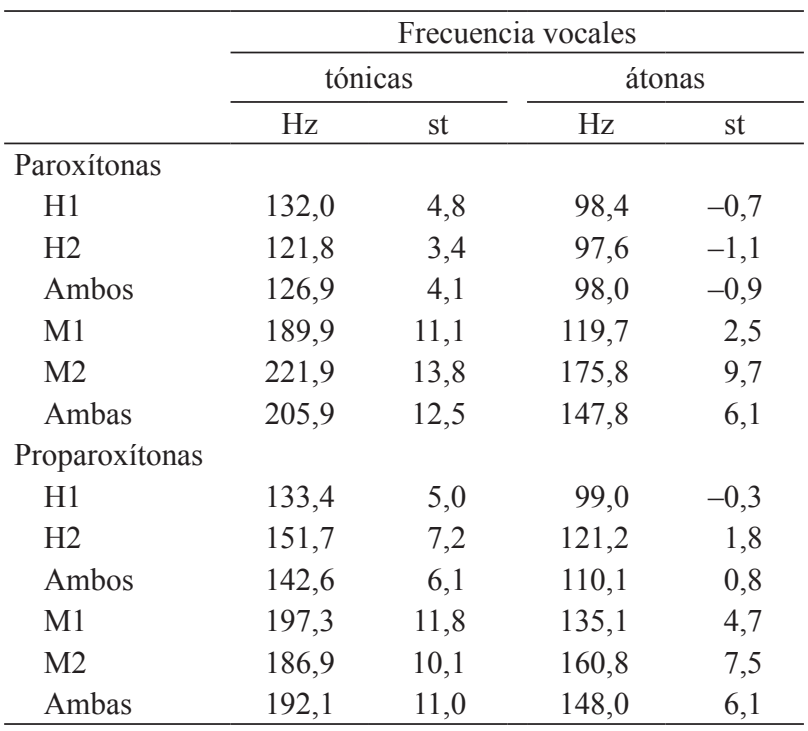

ponde a ninguna medida concreta sino que es relativa, es decir, una categorización. Por ejemplo, el primer tono es alto respecto a los otros tres, pero lo verdaderamente contrastivo no es que aparezca el valor 5, sino el hecho de que sea una o varias unidades más alto que los valores medios de otros tonos. Cuando las palabras españolas son pronunciadas aisladamente, la frecuencia de la vocal tónica es, normalmente, superior a la de la vocal átona, hecho conocido que, además, hemos reflejado en la Tabla 2 con las medias de cada informante. Esta característica es análoga a la que nos permite afirmar que el primer tono chino es más alto que el resto.

Debemos tener en cuenta, además, que el oído percibe con dificultad variaciones inferiores a 1,5 $\mathrm{st}^{3}$ en el reducido periodo de tiempo que dura una sílaba. En la práctica se considera que una sílaba presenta un tono sostenido a lo largo de su producción si su diferencia tonal ${ }^{4}$ es menor que $1,5 \mathrm{st}$.

De todo lo anterior se desprende que en el caso de las paroxítonas y proparoxítonas, si la diferencia tonal es menor que $1,5 \mathrm{st}$, es semejante a un contorno alto (en términos relativos a las demás sílabas como acabamos de mencionar) y sostenido (debido a la imperceptibilidad del cambio), como el primer tono del chino mandarín.

En cuanto a las oxítonas, según la descripción de datos, si la variación tonal es negativa, indica un contorno descendente ( $\$ 3.5)$, por lo cual si este valor es menor o igual que $-1,5 \mathrm{st}$, la vocal tónica se realiza con una bajada relevante que es semejante al cuarto tono del chino mandarín.
Nuestras hipótesis pueden formularse ahora de la siguiente manera:

Hipótesis 1: En las palabras paroxítonas (no hiatos) y proparoxítonas pronunciadas aisladamente, no en un contexto de frase, el valor absoluto de la variación tonal ${ }^{5}$ (diferencia tonal) es menor que $1,5 \mathrm{st}$.

Hipótesis 2: En las palabras oxítonas pronunciadas aisladamente (no en un contexto de frase) la variación tonal es menor o igual que $-1,5$ st.

Antes de analizar con detenimiento los datos obtenidos, conviene observar unos gráficos del contorno tonal del acento léxico del español en distintos tipos de palabras producidas por nuestros informantes. Observamos que en la Figura 2 y la Figura 3, correspondientes respectivamente a una palabra paroxítona y una proparoxítona, el contorno de la vocal tónica es sostenido y además, alto respecto a la vocal átona, similar al primer tono del chino mandarín. En la Figura 4, el contorno de la vocal tónica de la palabra oxítona es descendente, como el cuarto tono del chino mandarín.

Figura 2. Ejemplo del contorno tonal del acento léxico en palabras paroxítonas. $\mathrm{A}=$ vocal tónica $[\mathrm{a}]$.

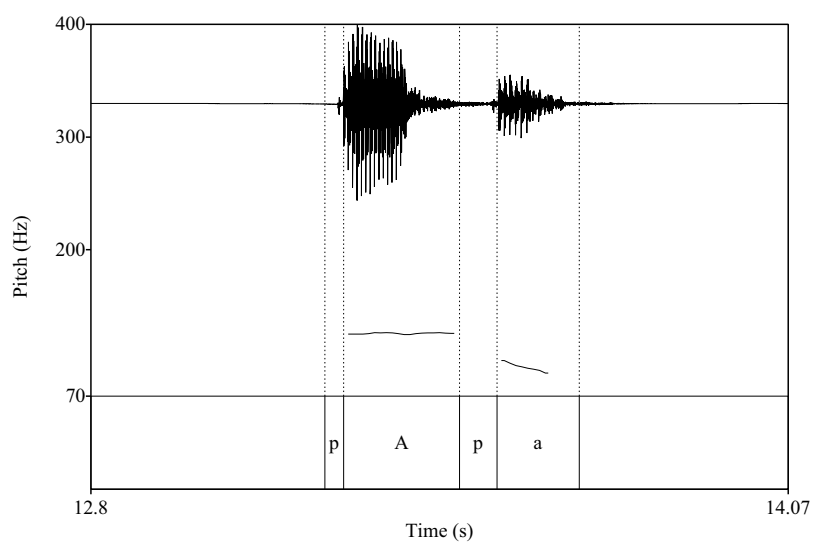

\subsubsection{Verificación de las hipótesis reformuladas}

Primero realizamos análisis general. En la Tabla 1, con palabras pronunciadas por hombres, la media de la diferencia tonal de todas las paroxítonas es de $0,8 \mathrm{st}$, cumpliéndose la hipótesis 1 . Además, en la Tabla 2 se observa que la frecuencia media de la vocal tónica es mayor que la de las átonas, lo que hace que este caso sea asimilable con precisión al primer tono del chino mandarín, que es más alto que los otros tres. Deducimos lo mismo con las proparoxítonas, dado que la diferencia tonal media es 0,7 st.

\footnotetext{
${ }^{3}$ El umbral de 1,5 st fue establecido para la percepción entre la sílaba tónica y las átona de una palabra española en Pamies Bertrán, Fernández Planas, Martínez Celdrán, Ortega Escandell y Amorós Céspedes (2002), citado por Fernández Planas y Martínez Celdrán (2003, p. 173).

${ }^{4}$ Nótese que tal como se ha definido $(\$ 3.5)$, la diferencia tonal siempre es un valor positivo.

${ }^{5}$ Nótese que tal como se ha definido $(\S 3.5)$, la variación tonal de una palabra refleja solo características relativas a su vocal tónica.
} 
Figura 3. Ejemplo del contorno tonal del acento léxico en palabras proparoxítonas. $\mathrm{E}=$ vocal tónica $[\mathrm{e}]$.

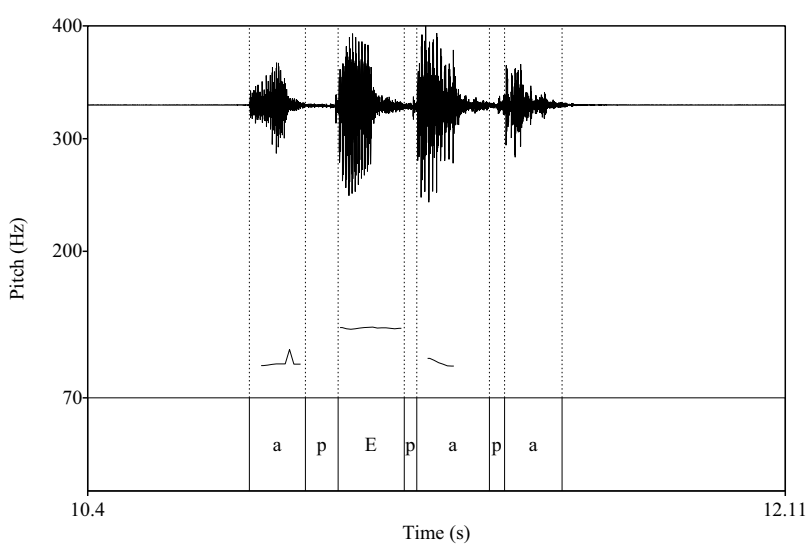

Figura 4. Ejemplo del contorno tonal del acento léxico en palabras oxítonas. I = vocal tónica [i].



Respecto a las oxítonas, la variación tonal media es $-2,5$ st, verificándose la hipótesis 2 , es decir, su contorno es parecido al cuarto tono del chino mandarín.

En el caso de las palabras pronunciadas por mujeres, podemos observar unos rasgos similares a los de hombres. Las medias de las variaciones tonales son $0,7 \mathrm{st}, 1,2$ st y $-2,6$ st en paroxítonas, proparoxítonas y oxítonas, respectivamente, así que comprobamos que nuestras hipótesis son válidas también para las mujeres.

Para realizar un análisis más detallado, mostramos en la Tabla 3, para cada vocal y para cada tipo de palabra, el porcentaje de producciones paroxítonas y proparoxítonas que presentan $D T<1,5$ st y $D T \geq 1,5 \mathrm{st}$, y el porcentaje de producciones oxítonas con $V T \leq-1,5$ st y $V T>-1,5$ st. Como podemos observar, en las palabras paroxítonas y proparoxítonas la mayoría de los casos tiene una diferencia tonal de menos de 1,5 st en las cinco vocales tónicas; en otros términos, el contorno de todas es alto (siendo la vocal tónica) y sostenido, parecido al primer tono del chino mandarín. En las palabras oxítonas, la mayoría de los casos tiene una variación tonal de menos de $-1,5$ st en las cinco vocales tónicas, es decir, el contorno de todas es descendente, parecido al cuarto tono del chino mandarín.
Tabla 3. Porcentajes en semitonos (st) de variaciones tonales y diferencias tonales respecto a $1,5 \mathrm{st}$ y $-1,5 \mathrm{st}$.

\begin{tabular}{lcrrrr}
\hline Palabras & {$[\mathrm{i}]$} & {$[\mathrm{e}]$} & {$[\mathrm{a}]$} & {$[\mathrm{o}]$} & {$[\mathrm{u}]$} \\
\hline Paroxítonas & & & & & \\
$\quad D T \geq 1,5$ st (\%) & 0,0 & 8,3 & 0,0 & 8,3 & 8,3 \\
$\quad D T<1,5$ st (\%) & 100 & 91,7 & 100 & 91,7 & 91,7 \\
\hline Proparoxítonas & & & & & \\
$D T \geq 1,5$ st (\%) & 33,3 & 27,3 & 8,3 & 8,3 & 8,3 \\
$D T<1,5$ st (\%) & 66,7 & 72,7 & 91,7 & 91,7 & 91,7 \\
\hline Oxítonas & & & & & \\
$D T \leq-1,5$ st (\%) & 75,0 & 73,3 & 62,5 & 81,3 & 87,5 \\
$D T<-1,5$ st (\%) & 25,0 & 26,7 & 37,5 & 18,8 & 12,5 \\
\hline
\end{tabular}

También es evidente que existen diferencias entre los porcentajes de las cinco vocales. Algunos son muy parecidos $(91,7 \%$ y $100 \%)$, y otros, un poco menos $(66,7 \%$ y $91,7 \%$, o $62,5 \%$ y $87,5 \%$ ). Sin embargo, no hay una regularidad que indique que nuestras hipótesis no se verifiquen para cierta vocal. Los casos desfavorables para las hipótesis pueden ser causados por el estado de los informantes, los cuales no tenían experiencia y estaban un poco nerviosos, y por tanto no pronunciaban algunos vocablos como palabras aisladas. De hecho, en las tablas puede observarse que hay variaciones tonales positivas en palabras oxítonas, lo cual parece contradecir nuestra hipótesis 2 . Sin embargo, escuchando atentamente esas grabaciones concretas, se percibe que la pronunciación en esos casos es totalmente deficiente. Es un aspecto que hay que mejorar en el futuro.

Generalmente no vemos que el número de sílabas afecte a la validez de nuestras hipótesis. Tampoco la condición de tener o no una consonante delante o detrás de la vocal tónica. No obstante, conviene destacar una característica de los datos. En las proparoxítonas, algunas de las palabras con la sílaba tónica sin consonante delante de la vocal tienen una diferencia tonal mayor que 1,5 st. Puede que en este caso influya la inexistencia de la consonante, aunque no ha afectado al resultado final de este experimento. Esto se podrá comprobar con más informantes, un corpus más amplio o las dos condiciones según sea necesario.

\subsubsection{Conversión en valores de cinco niveles}

Según la norma estándar, el contorno del primer tono del chino mandarín es alto y sostenido [55], el segundo es ascendente [35], el tercero es bajo y descendente-ascendente [214] y el cuarto es descendente [51]. Los números, definidos por el modelo de cinco niveles de Chao (1930/2006), son valores relativos que sirven para calcular la variación tonal del principio al final de cada sílaba. Por ejemplo, el primer tono tiene una variación tonal de 0 nivel $(5-5)$; el segundo, de $2(5-3)$; el tercero, de 
$-1(-(2-1))$ y $3(4-1)$; y el cuarto, de $-4(-(5-1))$. Sin embargo, como hemos indicado en $\S 2.1 .1$, en la producción real de una sílaba es bastante difícil realizar los cuatro tonos con sus perfiles exactos, por lo que son más bien puntos de referencia. Por ejemplo, no es preciso que la variación tonal de una sílaba producida por un hablante concreto sea exactamente 0 o -4 niveles para ser considerado un primer o cuarto tono respectivamente. Importa más la tendencia (signo) de la evolución del contorno que los valores concretos.

A través de la fórmula (3) que hemos expuesto en $\S$ 2.1.2, convertiremos los valores medios de las frecuencias máximas y mínimas de la vocal tónica de cada tipo de palabras producidas por cada informante a valores correspondientes dentro del sistema de cinco niveles con el motivo de comparar, de manera más directa, el contorno tonal del acento léxico con los dos tonos del chino mandarín.

La Tabla 4 nos indica que en todas las producciones de vocal tónica de $\mathrm{H} 1$, la frecuencia máxima de su campo tonal es $147,4 \mathrm{~Hz}(6,7 \mathrm{st})$ y la mínima es $97,3 \mathrm{~Hz}(-0,5 \mathrm{st})$. Es decir, $A=6,7$ y $B=-0,5$. La media de las frecuencias máximas de la vocal tónica de las palabras paroxítonas producidas por dicho informante es $134,2 \mathrm{~Hz}(5,1 \mathrm{st})$. Es decir, $X=5,1$. Por tanto,

$$
T_{\text {máx }}=5 \frac{X-B}{A-B}=5 \times \frac{5,1-(-0,5)}{6,7-(-0,5)} \approx 3,9 .
$$

La media de las frecuencias mínimas de la vocal tónica de las mismas producciones es $128 \mathrm{~Hz}$ (4,3 st), entonces $X=4,3$. Por tanto,

$$
T_{\text {mín }}=5 \frac{4,3-(-0,5)}{6,7-(-0,5)} \approx 3,3 .
$$

Puesto que ambos valores de la vocal tónica de las palabras paroxítonas pronunciadas por $\mathrm{H} 1, T_{\text {máx }}=3,9 \mathrm{y}$ $T_{\text {mix }}=3,3$, están en el intervalo $[3,4]$, corresponden al valor 4 del sistema de cinco niveles de Chao (1930/2006) (§ 2.1.2). En otros términos, el acento léxico de dichas palabras tiene un contorno tonal [44], que es alto y sostenido, muy parecido al primer tono estándar [55] del chino mandarín, aunque hay una unidad de diferencia entre los dos. De hecho, en chino mandarín el contorno [44] también se considera como el primer tono, dado que dentro de los cuatro tonos léxicos no existe uno que también se sitúe en el estrato alto (nivel 4 y 5) para contrastar con el contorno [55] sólo por el registro tonal. Para los cuatro tonos del chino mandarín, lo más significativo es la dirección de la evolución de f0 a lo largo del tono. Por ejemplo, Shi (2008) en sus experimentos comprueba que el primer tono presenta el contorno [44]. Hu (1993) también confirma que, aparte del contorno estándar [55], el [44] e incluso el [33] pueden servir como primer tono.

Del mismo modo obtuvimos todos los contornos tonales de las vocales tónicas dentro del mismo campo tonal de cinco niveles según hablante y tipo de palabras:
Tabla 4. Campo tonal de los informantes en la producción de las vocales tónicas y valores medios de las frecuencias máximas y mínimas de las vocales tónicas por hablante y según tipo de palabras. $\mathrm{H} 1=$ Hombre 1, H2 = Hombre 2, M1 = Mujer

\begin{tabular}{|c|c|c|c|c|c|c|c|c|}
\hline & \multirow{2}{*}{\multicolumn{2}{|c|}{$\begin{array}{l}\text { Valores del } \\
\text { campo tonal }\end{array}$}} & \multicolumn{6}{|c|}{ Medias de valores de frecuencia } \\
\hline & & & \multicolumn{2}{|c|}{ Paroxítonas } & \multicolumn{2}{|c|}{ Proparoxítonas } & \multicolumn{2}{|c|}{ Oxítonas } \\
\hline & $\mathrm{Hz}$ & st & $\mathrm{Hz}$ & st & $\mathrm{Hz}$ & st & $\mathrm{Hz}$ & st \\
\hline \multicolumn{9}{|l|}{ H1 } \\
\hline máximo & 147,4 & 6,7 & 134,2 & 5,1 & 135,2 & 5,2 & 132,4 & 4,9 \\
\hline mínimo & 97,3 & $-0,5$ & 128,0 & 4,3 & 130,7 & 4,6 & 114,5 & 2,3 \\
\hline \multicolumn{9}{|l|}{$\mathrm{H} 2$} \\
\hline máximo & 163,6 & 8,5 & 123,8 & 3,7 & 154,5 & 7,5 & 129,5 & 4,5 \\
\hline mínimo & 94,6 & $-0,9$ & 118,8 & 3,0 & 147,4 & 6,7 & 109,8 & 1,6 \\
\hline \multicolumn{9}{|l|}{ M1 } \\
\hline máximo & 242,9 & 15,4 & 193,3 & 11,4 & 202,0 & 12,2 & 210,6 & 12,9 \\
\hline mínimo & 138,5 & 5,6 & 185,5 & 10,7 & 191,2 & 11,2 & 167,9 & 9,0 \\
\hline \multicolumn{9}{|l|}{ M2 } \\
\hline máximo & 244,8 & 15,5 & 224,9 & 14,0 & 222,7 & 13,9 & 188,2 & 11,0 \\
\hline mínimo & 111,7 & 1,9 & 111,7 & 1,9 & 111,7 & 1,9 & 169,9 & 9,2 \\
\hline
\end{tabular}
1, M2 = Mujer 2; st $=$ semitonos.

- H1: paroxítonas [44], proparoxítonas [44], oxítonas [42].

- H2: paroxítonas [33], proparoxítonas [55], oxítonas [32].

- M1: paroxítonas [33], proparoxítonas [43], oxítonas [42].

- M2 paroxítonas [55], proparoxítonas [55], oxítonas [43].

Incorporamos estos datos al diagrama de representación de los tonos del chino con el fin de ilustrar las equivalencias con el acento léxico del español (Figura 5).

Figura 5. Contornos tonales del acento léxico del español en cinco niveles.

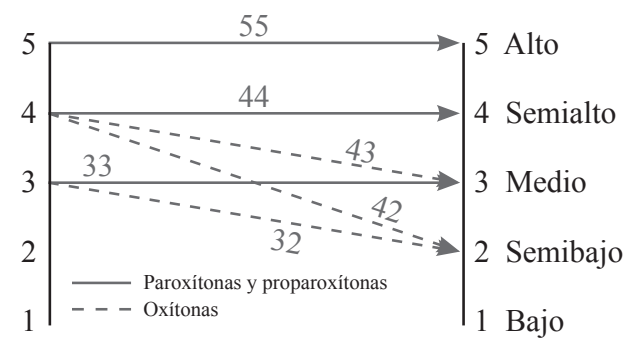

En la Figura 5 no se especifica detalladamente la magnitud tiempo en el eje horizontal, dado que hemos comprobado anteriormente que el contorno tonal del acento léxico de las palabras oxítonas es descendente, y que el de las paroxítonas y proparoxítonas es sostenido dentro de los límites perceptivos. Para nuestro trabajo no es im- 
portante la duración concreta de cada producción, que está sujeta a muchas variaciones, sino el contorno tonal. De este modo, nuestras hipótesis están reflejadas directamente en la Figura 5. Se observa, salvo en el caso de las proparoxítonas de M1, que los contornos tonales del acento léxico de las palabras paroxítonas y proparoxítonas por una parte, y el de las oxítonas por otra, son parecidos e incluso idénticos al primer [55] y al cuarto tono estándar [51] del chino mandarín, respectivamente (véase la Figura 1).

Por otro lado, al examinar atentamente los cinco niveles, el registro del acento léxico no siempre coincide con el de los dos tonos. Sin embargo, eso no contradice nuestras hipótesis, puesto que en general el acento léxico de las palabras paroxítonas y proparoxítonas presenta un contorno sostenido, el cual es alto respecto a las sílabas átonas (véase la Tabla 2). Dichas sílabas se pueden considerar semejantes al tono neutro del chino mandarín $(\S$ 2.1). Por tanto, el contorno que hemos obtenido es alto y sostenido como el primer tono del chino mandarín.

El acento léxico de las oxítonas presenta un contorno descendente, aunque la variación tonal no coincide exactamente con la del cuarto tono del mandarín. Como exponíamos anteriormente, el rasgo distintivo de los tonos chinos es hacia dónde apunta la evolución de $f_{0}$. Entre los cuatro tonos no existe más que un tono descendente, de ahí que no haya lugar para la confusión con otros tonos, sobre todo para la percepción de los nativos. Es más, en el habla real es muy difícil encontrar un tono producido exactamente con su registro definido por el estándar. Por ejemplo, Hu (1993) señala que aparte del contorno [51], el [53] y el [42] también pueden servir como cuarto tono. Podemos afirmar que el contorno tonal del acento léxico de las palabras oxítonas es similar al cuarto tono del chino mandarín por su dirección de evolución.

\section{CONCLUSIONES}

En este trabajo hemos demostrado que existen grandes similitudes entre el contorno del acento léxico del español y dos tonos del chino mandarín a través de un experimento con palabras pronunciadas aisladamente, y de esta manera hemos establecido la veracidad de las hipótesis que propusimos al principio. En concreto:

1. El contorno tonal de la vocal tónica de las palabras paroxítonas (no hiatos) y proparoxítonas del español pronunciadas aisladamente (no en un contexto de frase) es parecido o incluso igual que el primer tono estándar del chino mandarín.

2. El contorno tonal de la vocal tónica de las palabras oxítonas del español pronunciadas aisladamente (no en un contexto de frase) es parecido o incluso igual que el cuarto tono estándar del chino mandarín.

Destaquemos también que la validez de nuestros resultados es independiente de la vocal considerada.
Dichas similitudes podrían servir como un fundamento teórico para la enseñanza del español a sinohablantes y del chino a hispanohablantes en la producción del acento léxico en palabras aisladas y de los tonos de cada sílaba, sobre todo al inicio del proceso de la enseñanza-aprendizaje. Por ejemplo, los alumnos chinos están familiarizados con los tonos estándar del mandarín, por lo que se podría utilizar este hecho para establecer una estrategia que permita a los principiantes dominar la sílaba tónica de las palabras españolas, al menos al pronunciarlas aisladamente $\mathrm{y}$, a partir de ahí, estudiar y hacer propuestas con frases. Los estudiantes españoles también podrían trasladar los tonos de las sílabas tónicas para producir los tonos chinos.

La descripción de los tonos del chino mandarín está basada en estudios anteriores. No hemos hecho grabaciones adicionales. En una futura investigación, y con el fin de obtener resultados que ofrezcan valores cercanos a un estilo de habla más natural, se podrían realizar grabaciones de palabras del chino siguiendo el mismo procedimiento que se utilizó para grabar las del español. Así, además, estaríamos aplicando exactamente la misma metodología a la recopilación de todo el corpus. Creemos que, de este modo, los contornos del acento léxico del español y los dos tonos (el primero y el cuarto) del chino mandarín resultarían ser incluso más parecidos que con los valores estándar. Por otro lado, también se podrían hacer pruebas de percepción con hablantes nativos de cada idioma sustituyendo el elemento de análisis con su equivalencia en el otro idioma.

Sobre el caso de las proparoxítonas de M1, necesitaríamos más datos de más hablantes para comprobar estadísticamente si es un outlier.

Otro punto para mencionar aquí es el proceso técnico para adquirir los datos del experimento. Diseñamos dos scripts con Praat sólo para conseguir los valores principales. En realidad, se puede automatizar todo el proceso creando una función con los scripts, de manera que podamos ahorrar mucho trabajo manual. En todo caso, la automatización de medir $f_{0}$ aún requiere bastante supervisión por parte de un ser humano para mantener la confiabilidad de los datos.

En resumen, hemos encontrado similitudes entre dos idiomas muy diferentes y nuestras hipótesis han quedado comprobadas. La fiabilidad de los resultados obtenidos nos incita a ampliar esta línea de investigación, siendo la consideración de los diptongos un siguiente paso razonable. En una etapa posterior, podría ser interesante abordar la realización de estudios comparativos en contextos de frase.

\section{REFERENCIAS}

Chao, Y. R. (1922).中国言语字调底实验研究法[Experimental methodology on Chinese tone values]. 《科学》[Science], 7(9), 871-882.

Chao, Y. R. (2006). A system of «Tone-letters». En Z. J. Wu \& X. N. Zhao (Eds.), Linguistic essays by Yuenren Chao (pp. 98102). Beijing: The Commercial Press (reeditado de la obra de 1930 Le Maître Phonétique, troisième série, 30, 24-27). 
Comité Nacional de Lengua y Escritura (2004). 《普通话水平测试 实施纲要》[Normativa para el examen de putonghua]. Beijing: The Commercial Press.

Enríquez, E. V., Casado, C., \& Santos, A. (1989). La percepción del acento en español. Lingüística Española Actual, 11(2), 241-269.

Fernández Planas, A. M., \& Martínez Celdrán, E. (2003). El tono fundamental y la duración: Dos aspectos de la taxonomía prosódica en dos modalidades de habla (enunciativa e interrogativa) del español. Estudios de Fonética Experimental, XII, 165-200.

Hu, B. H. (1993). 普通话的轻声问题 [Sobre el tono neutro del $p u$ tonghua]. 《中国语文通讯》 [Newsletter of Chinese Language ], 25, 11-18. The Chinese University of Hongkong.

Lin, M. C. (1965). 音高显示器与普通话声调音高特性 [The pitch indicator and the pitch characteristics of tones in standard chinese]. 《声学学报》[Chinese Journal of Acoustics], 2(1). Beijing: Science Press.

Lin, T. (1985). Preliminary experiments on the nature of Mandarin neutral tone. En T. Lin \& L. J. Wang (Eds.), 《北京语音实验 录》[Working papers in experimental phonetics] (pp. 1-26). Beijing University Press

Lin, T. (1990).《语音探索集稿》[Essays on phonetic research]. Beijing Language and Culture University Press.

Llisterri, J., Machuca, M. J., de la Mota, C., Riera, M., \& Ríos, A. (2005). La percepción del acento léxico en español. En Filología y lingüística: Estudios ofrecidos a Antonio Quilis,
Vol. 1, 271-297. Madrid: Consejo Superior de Investigaciones Científicas.

Pamies Bertrán, A., Fernández Planas, A. M., Martínez Celdrán, E., Ortega Escandell, A., \& Amorós Céspedes, M. C. (2002). Umbrales tonales en español peninsular. En Actas del II Congreso de fonética experimental (pp. 272-278). Universidad de Sevilla.

Quilis, A. (1971). Caracterización fonética del acento español. Travaux de Linguistique et de Littérature, 9, 53-72.

Rose, P. (2014). Transcribing Tone-A likelihood-based quantitative evaluation of Chao's «tone letters». $15^{\text {th }}$ Annual Conference of the International Speech Communication Association (INTERSPEECH'14), 101-105.

Shi, F. (2008). 《语音格局-语音学与音系学的交汇点》[Sound pattern - The intersection of phonetics and phonology]. Beijing: The Commercial Press.

Shi, F. (2009). Exploration of experimental phonology. Peking University Press.

Tsukuma, Y. (1988). Neutral tones in Mandarin Chinese: An analysis based on acoustic-phonetic data. Beacon, 23, 29-54.

Wang, L. (2003). 《播音员主持人训练手册》 [Manual de formación de presentadores y locutores]. Beijing: Communication University of China Press.

Xu, Y., \& Xu, C. X. (2005). Phonetic realization of focus in English declarative intonation. Journal of Phonetics, 33, 159-197. http://dx.doi.org/10.1016/j.wocn.2004.11.001. 